\title{
Article
}

\section{Cast metal cap splint use for immobilisation of mandibular fracture.}

\author{
Yuffa, AD, Bruzual, LM, Hammond, D and Whear, NM \\ Available at http://clok.uclan.ac.uk/16444/ \\ Yuffa, AD, Bruzual, LM, Hammond, D and Whear, NM (2014) Cast metal cap \\ splint use for immobilisation of mandibular fracture. Oral Surgery, 8 (1). pp. \\ 63-64. ISSN 1752-2471
}

It is advisable to refer to the publisher's version if you intend to cite from the work. http://dx.doi.org/10.1111/ors.12124

For more information about UCLan's research in this area go to http://www.uclan.ac.uk/researchgroups/ and search for <name of research Group>.

For information about Research generally at UCLan please go to http://www.uclan.ac.uk/research/

All outputs in CLoK are protected by Intellectual Property Rights law, including Copyright law. Copyright, IPR and Moral Rights for the works on this site are retained by the individual authors and/or other copyright owners. Terms and conditions for use of this material are defined in the policies page.

\section{CLoK}

Central Lancashire online Knowledge www.clok.uclan.ac.uk

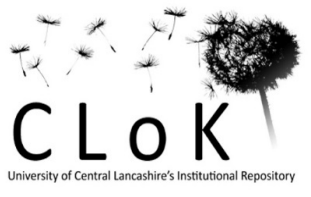


CASE REPORT

\title{
Cast metal cap splint use for immobilisation of mandibular fracture
}

\author{
A.D. Yuffa, L.M. Bruzual, D. Hammond \& N.M. Whear \\ Dudley Group of Hospitals NHS Trust, Russells Hall Hospital, Dudley, UK
}

\author{
Key words: \\ intermaxillary fixation, mandible fracture, metal \\ cap splints, splints \\ Correspondence to: \\ DrAD Yuffa \\ Dudley Group of Hospitals NHS Trust \\ Russells Hall Hospital \\ Dudley DY12HQ \\ UK \\ Tel.: +4401384456111 \\ Fax: +4401384244169 \\ email:arie.yuffa@nhs.net
}

Accepted: 2 July 2014

doi:10.1111/ors.12124

\begin{abstract}
Use of cast metal cap splints in a patient with multiple fractures to sphenoid, zygoma, orbital floor and mandible unable to receive surgical treatment for reduction and fixation of fractured segments due to cervical spine fractures; technique considered in disuse by many.
\end{abstract}

\section{Case report}

A 38-year-old male patient presented to the emergency department with injuries that were sustained after falling down a flight of steps under the influence of alcohol. The patient had a Glasgow Coma Score of 15 throughout, and apart from his facial injuries he complained of paraesthesia of his left arm, in the $\mathrm{C} 7 / \mathrm{C} 8$ dermatomal distribution.

Clinical examination and relevant radiographic investigations revealed extensive comminuted displaced fractures involving his left sphenoid bone, left zygomatic arch, left orbital floor and also a fracture of the left body of the mandible (Fig. 1). Computed tomography scans of the cervical spine revealed fractures of C6 and C7 with narrowing of the cervical spine canal and with associated facet joint dislocations.

The neurosurgical team decided to treat the cervical spine injuries conservatively. Having reviewed the patient with the ophthalmology team, our findings were that the patient had no diplopia and had no obvious asymmetry as a result of the orbitozygomatic injury. Therefore, after discussion with the patient, it was decided that the only injury that required intervention was that of the fractured mandible.
However, to perform an open reduction internal fixation of his mandible conventionally under general anaesthetic would mean that the patient would be under greater risk of displacement of his spinal fractures due to the flexing and extension of his neck during intubation or extubation. As conventional treatment would have risked damage to the spinal cord, we had to use an alternative method of fixation.

A decision was made to reduce the fracture with the use of cast metal cap splints (Fig. 2), a rigid fixation method that has been used for more than 50 years in the UK ${ }^{1,2}$. This method was chosen, as this could be performed under local anaesthetic. By performing this under local anaesthetic, it reduced the risk of displacement of his spinal fracture. It also meant that the patient was awake and alert and could inform us if he had any neck pain throughout the procedure.

Maxillary and mandibular impressions were taken in an alginate impression material. The lower impression was sectioned, and both upper and lower models were mounted on an articulator to reproduce the patient's occlusion. Upper and lower cap splints were fabricated, with the lower constructed in two parts, each with a soldered locking plate ${ }^{1}$. These segments were joined 


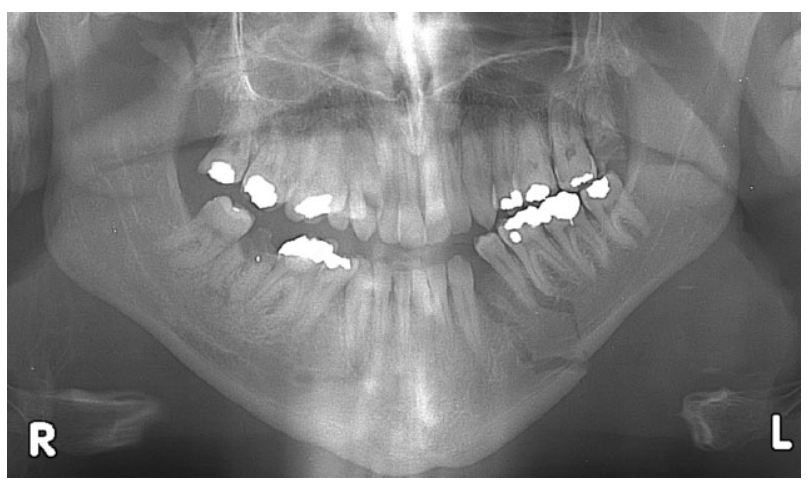

Figure 1 Orthopantomography showing fractured site.

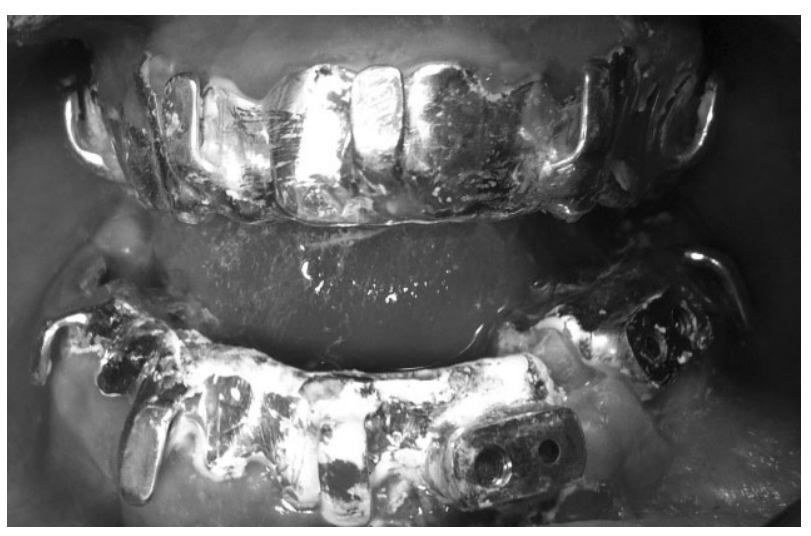

Figure 2 Intraoral photography: cap splints cemented but still not locked.

with a bar screwed to each locking plate, thus aligning and reducing the fracture to its correct anatomical position ${ }^{3}$.

The patient was taken to theatre, and local anaesthetic was administered. The fracture was reduced by manipulation of the mandible into its correct anatomical position. The metal cap splints were cemented with glass ionomer cement. The locking plate was easily applied and secured with two screws, thus rigidly immobilising the fracture. A 24 -h period was allowed for secondary setting of the glass ionomer cement prior to applying elastic intermaxillary fixation.

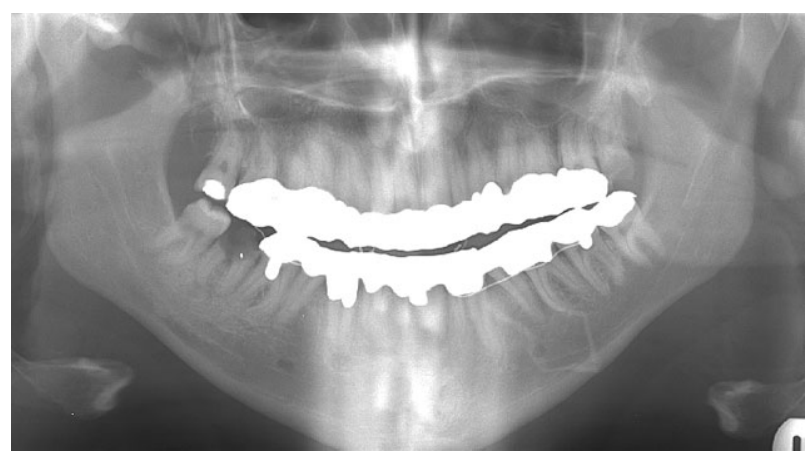

Figure 3 Orthopantomography: 6 weeks after Inter-maxillary Fixation (IMF).

Six weeks later the cast metal splints were removed. Radiographs revealed satisfactory reduction of the fracture and evidence of good bony healing (Fig. 3). Clinically, the patient had an excellent occlusion. His other facial injuries healed well, and no surgical intervention has been required.

This method shows that we should not disregard techniques that may be considered old fashioned ${ }^{4}$ and demonstrates that they still have a place in the modern treatment of the fractured mandible.

\section{Acknowledgement}

David Heath, Maxillofacial Lab Technician, for the excellent work and fabrication of cast metal cap splints.

\section{References}

1. Robertson JH. Recent advances in maxillofacial surgery dental splints. Proc R Soc Med 1964;57(3):184.

2. Bainton R, Davies ES. The broadgreen osteotomy splint. Br J Oral Maxillofac Surg 1989;27(1):80-2.

3. McGregor AJ. An adjustable locking plate for sectional metal cap splints: a further report. Br J Oral Surg 1971;9(3):251-4.

4. Banks P, Brown A. Fractures of the Facial Skeleton. London: Wright/Elsevier, 2001:97-8. 